\section{Evaluation of hygiene and safety criteria in the production of a traditional Piedmont cheese}

\author{
Sara Astegiano, ${ }^{1}$ Alberto Bellio, ${ }^{1}$ \\ Daniela Adriano, \\ Daniela Manila Bianchi, ${ }^{1}$ \\ Silvia Gallina, ${ }^{1}$ Alessandra Gorlier, ${ }^{2}$ \\ Monica Gramaglia, \\ Giampiero Lombardi, ${ }^{2}$ Guerrino Macori, ${ }^{1}$ \\ Fabio Zuccon, ${ }^{1}$ Lucia Decastelli ${ }^{1}$ \\ 'Struttura Complessa del Controllo \\ Alimenti e Igiene delle Produzioni, \\ Istituto Zooprofilattico Sperimentale del \\ Piemonte, Liguria e Valle d'Aosta, Torino; \\ 2Dipartimento di Agronomia, Selvicoltura \\ e Gestione del Territorio, Università degli \\ Studi di Torino, Italy
}

\section{Abstract}

Traditional products and related processes must be safe to protect consumers' health. The aim of this study was to evaluate microbiological criteria of a traditional Piedmont cheese, made by two different cheese producers ( $\mathrm{A}$ and B). Three batches of each cheese were considered. The following seven samples of each batch were collected: raw milk, milk at $38^{\circ} \mathrm{C}$, curd, cheese at 7, 30, 60, 90 days of ripening. During cheese making process, training activities dealing with food safety were conducted. Analyses regarding food safety and process hygiene criteria were set up according to the EC Regulation 2073/2005. Other microbiological and chemical-physical analyses [lactic streptococci, lactobacilli, $\mathrm{pH}$ and water activity $\left(A_{w}\right)$ ] were performed as well. Shiga-toxin Escherichia coli, aflatoxin M1 and antimicrobial substances were considered only for raw milk. All samples resulted negative for food safety criteria; Enterobacteriaceae, E.coli and coagulase-positive staphylococci (CPS) were high in the first phase of cheese production, however they decreased at the end of ripening. A high level of CPS in milk was found in producer A, likewise in some cheese samples a count of $>5 \mathrm{Log} \mathrm{CFU} / \mathrm{g}$ was reached; staphylococcal enterotoxins resulted negative. The $\mathrm{pH}$ and $A_{w}$ values decreased during the cheese ripening period. The competition between lactic flora and potential pathogen microorganisms and decreasing of $\mathrm{pH}$ and $\mathrm{A}_{\mathrm{w}}$ are considered positive factors in order to ensure safety of dairy products. Moreover, training activities play a crucial role to manage critical points and perform corrective action. Responsible application of good manufacturing practices are con- sidered key factors to obtain a high hygienic level in dairy products.

\section{Introduction}

Recently, there has been a renewed interest in Italian traditional mountain food products because of the unique environmental conditions of the Alps, in the north of Italy (Povolo et al., 2013). Processing and preservation methods of the traditional Italian food products have been consolidated over time. They have been produced according to traditional Italian regulations for 25 years. According to the Italian Ministry of Agriculture and Forestry list (updated in January 2014), 259 out of 4000 traditional products are certified as protected designation of origin and protected geographical indication (MiPAAF, 2014). These products play an important role for the small local producers: tradition and guaranteed origins are the most significant features appreciated by consumers. However, traditional products and manufacturing must be safe; in fact, according to the EC Regulation 2073/2005 (European Commission, 2005) the process hygiene criteria and food safety criteria are required for all foodstuffs, in order to protect consumer's health.

Therefore, two aspects are crucial: on the one hand controlling of chain production to identify the phases at risk and, on the other establishing and observing of good manufacturing practices. This study was conducted on a typical Italian mountain cheese called Toma tipo Piemonte; two producers in the west area of Turin province, one located in the Chisone valley (A) and one in the Sangone valley (B) were involved. This study fomulates three main objectives: i) the development of training courses about hygienic problems occurring during cheese making process at dairy plants; ii) the characterisation of cheese making process, through data collection at different stages; iii) the evaluation of hygienic features of the process in compliance with food safety criteria.

\section{Materials and Methods}

The development of training courses at local producers was set up by the expertise of the Istituto Zooprofilattico Sperimentale of Piemonte, Liguria and Valle d'Aosta (IZSPLV). The IZSPLV staff supported practically the producers during the whole cheese making process, explaining the correct hygiene practises during milking and cheese making processes. Training courses were performed at each dairy plants in order to know and solve
Correspondence: Sara Astegiano, Struttura Complessa del Controllo Alimenti e Igiene delle Produzioni, Istituto Zooprofilattico Sperimentale del Piemonte, Liguria e Valle d'Aosta, via Bologna 148, 10154 Torino, Italy.

Tel. +39.11.2686233 - Fax: +39.11.22473450.

E-mail: sara.astegiano@izsto.it

Key words: Cheese making process, Food safety, Traditional cheese, Piedmont.

Funding: this study was supported by the financial contribution of Chamber of Commerce, Industry, Crafts and Agriculture (CCIAA) of Turin, Northern Italy.

Received for publication: 13 May 2013. Revision received: 23 May 2014.

Accepted for publication: 23 May 2014.

This work is licensed under a Creative Commons Attribution 3.0 License (by-nc 3.0).

(C) Copyright S. Astegiano et al., 2014

Licensee PAGEPress, Italy

Italian Journal of Food Safety 2014; 3:1705

doi:10.4081/ijfs.2014.1705

specific problems. In fact structural characteristics and handling habits were so different between the two situations. In staff opinion, improving proper handling practices was more useful in order to achieve and memorise a correct behaviour. In addition, the staff was also available to evaluate the hurdles of the procedure and implement possible corrective actions following the results obtained from the cheese making processes. The characterisation of the cheese making process was carried out in the two above mentioned cheese producers with the features explained below.

\section{Producer A}

In winter cows are in the valley for breeding and the milk is processed in loco. In summer the herd is in the pasture breeding, where the Toma cheese is produced in small dairy plants. The Toma cheese making process was as follows: i) the evening milk was stored in a refrigerate tank at $+4^{\circ} \mathrm{C}$ and the day after the morning milk was added; ii) the milk was filtrated and transferred into an inox pot and heated up to $38^{\circ} \mathrm{C}$; iii) the powder rennet was added following a pause of 30-40 min for curdling; iv) the curd was cut into little pieces, with a pause of $5 \mathrm{~min}$; v) the curd was heated up to $38^{\circ} \mathrm{C}$, and then extracted in a mold; vi) the cheese was put into a brine tank for about $2 \mathrm{~h}$; vii) ripening was carried out on wooden shelves in a cellar for 60-90 days, turning over once a day.

\section{Producer B}

The milk was always processed in the valley dairy plant. The Toma cheese making process 
was as follows: i) the evening milk was stored in a refrigerate tank at $+4^{\circ} \mathrm{C}$ and the following day morning milk was added; ii) the milk was filtrated and transferred into a copper pot and heated up to $38^{\circ} \mathrm{C}$; iii) the powder rennet was added, with a pause of 30-40 min for curdling; iv) the curd was cut into little pieces; v) the curd was heated up to $38^{\circ} \mathrm{C}$ and then extracted in a mold; vi) the cheese was immersed in brine and pressed for $24 \mathrm{~h}$; vii) ripening was conducted on stone for $48 \mathrm{~h}$ with turn over once a day, following on wooden shelves in a cellar for 60-90 days, with periodic turn over.

Production of the two cheeses reported few differences that were considered irrelevant; for this reason it was not necessary to differentiate the sampling plan. Two out of the three analysed batches from producer A were produced in the mountain dairy plant; on the contrary, all three batches from producer B were collected in the valley dairy plant.

Overall, three batches of the Toma cheese from A (1A-2A-3A) and three from B (1B-2B3B) were sampled; each batch formed by 7 samples. In particular, the following samples were collected: raw milk, milk at $38^{\circ} \mathrm{C}$, curd, cheese at 7, 30, 60, 90 days of ripening. In order to evaluate cheese microbiological parameters and hygienic process criteria, the analyses listed below were performed.

Food safety criteria (Reg. EC 2073/2005; European Commission, 2005): Listeria monocytogenes ISO 11290-1:1996 (ISO, 1996);
Salmonella spp. ISO 6579:2002/Cor. 1: 2004 (ISO, 2004c); Staphylococcal enterotoxins test (ELFA test, ANSES EU-CRL version 5, 2010), only if CPS $>5 \mathrm{Log}$ CFU/mL-g.

Process hygiene criteria: total microbial count (TMC) ISO 4833:2003 (ISO, 2003); $E$. coli ISO 16649-2:2001 (ISO, 2001); Enterobacteriaceae ISO 21528-2:2004 (ISO, 2004b); coagulase-positive staphylococci (CPS) IS0 6888-2:1999 (IS0, 1999).

Lactic bacteria: lactic streptococci internal method [M17 agar plates (Microbiol, Cagliari, Italy), incubated at $37^{\circ} \mathrm{C}$ for $48 \mathrm{~h}$ ]; lactobacilli internal method [de Man, Rogosa and Sharpe agar plates (Microbiol), incubated under anaerobic conditions at $37^{\circ} \mathrm{C}$ for $72 \mathrm{~h}$ ].

Furthermore, the $\mathrm{pH}$ value (method MFHPB03:2003) and the water activity ( $\mathrm{A}_{\mathrm{w}}$ ) (ISO 21807:2004; ISO, 2004a) were evaluated. Moreover, on raw milk samples the following analyses were set up: shiga-toxin Escherichia coli (STEC) ISO 13136/2011 (E. coli 026, 0103, 0111, 0145, 0157; ISO, 2011); aflatoxin M1 ELISA internal method (Tecna s.r.l., Sondrio, Italy); antimicrobial substances microbiological method Delvotest ${ }^{\circledast}$ SP NT (AOAC) (DSM Food Specialties, Heerlen, The Netherlands).

The results obtained from the different samples were calculated according to the ISO 7218:2007 (ISO, 2007). The mean of the values (CFU/mL or CFU/g) of three batches of each producer was calculated.

\section{Results}

\section{Producer $\mathrm{A}$}

The milk and the cheese samples were compliant to food safety criteria (Listeria monocytogenes and Salmonella spp.). Moreover, STEC, aflatoxin M1 and antimicrobial substances were not detectable in the raw milk. The TMC in the raw milk was $5.4 \mathrm{Log} \mathrm{CFU} / \mathrm{g}$, reaching a mean value of $8.4 \mathrm{Log}$ CFU/g in the cheese at 7 days of ripening, and remained constant until the end of ripening. The CPS grew from 3.1 Log CFU/mL in the milk up to $>5 \mathrm{Log} \mathrm{CFU} / \mathrm{g}$ in the curd and cheese at 7 days; the staphylococcal enterotoxins were not detectable. $E$. coli and Enterobacteriaceae developed during cheese production, reaching a maximum peak at 7 days, with a mean value of 3.4 and $5.3 \mathrm{Log}$ $\mathrm{CFU} / \mathrm{g}$, respectively. Lactic flora increased till 7 days and remained constant until the end of ripening with a count of $8.2 \mathrm{Log} \mathrm{CFU} / \mathrm{g}$. The $\mathrm{pH}$ decreased during cheese making process, getting to an average of 5.5 at 7 days and 5.6 at the end. The $A_{w}$ decreased till 60 days of ripening with a value of 0.963 and 0.968 in the final product. Results were summarised in Table 1.

\section{Producer B}

The milk and cheese samples were compliant to food safety criteria. Furthermore, STEC, aflatoxin M1 and antimicrobial substances were not detectable in the raw milk. The TMC

Table 1. Results of microbiological and compositional analyses in raw milk and cheese at production and at different ripening stages in Toma cheese (producer A).

\begin{tabular}{|c|c|c|c|c|c|c|c|c|}
\hline Sample & TMC & E. coli & Enterobacteriaceae & CPS & $\begin{array}{c}\text { Lactic } \\
\text { acid streptococci }\end{array}$ & Lactobacilli & $\mathrm{pH}$ & $\mathrm{A}_{\mathrm{w}}$ \\
\hline Raw milk (Log CFU/mL) & $5.4 \pm 0.2$ & n.d & 3.9 & $3.1 \pm 0.2$ & $5.1 \pm 0.6$ & $4.2 \pm 0.4$ & 6.8 & - \\
\hline Milk at $38^{\circ} \mathrm{C}(\mathrm{Log} \mathrm{CFU} / \mathrm{mL})$ & $6.8 \pm 0.4$ & $1.5 \pm 0.4$ & $4.6 \pm 0.5$ & $3.3 \pm 0.4$ & $6.5 \pm 0.4$ & $5.6 \pm 1.1$ & 6.8 & - \\
\hline Curd (Log CFU/g) & $7.9 \pm 0.5$ & $2.8 \pm 0.2$ & $5.2 \pm 0.7$ & $>5.0$ & $8.3 \pm 0.5$ & $6.9 \pm 1.5$ & 6.2 & - \\
\hline Cheese 7 days (Log CFU/g) & $8.4 \pm 0.05$ & $3.4 \pm 0.9$ & $5.3 \pm 0.7$ & $>5.0$ & $>8.2$ & $8.1 \pm 0.2$ & 5.5 & 0.970 \\
\hline Cheese 30 days (Log CFU/g) & $>8.5$ & $1.9 \pm 1.6$ & $2.3 \pm 1.4$ & $4.6 \pm 0.7$ & $>8.2$ & $>8.2$ & 5.4 & 0.969 \\
\hline Cheese 60 days (Log CFU/g) & $>8.5$ & $2.0 \pm 0.6$ & $2.3 \pm 0.6$ & $2.9 \pm 0.5$ & $>8.2$ & $>8.2$ & 5.5 & 0.963 \\
\hline Cheese 90 days (Log CFU/g) & $>8.5$ & n.d & $2.8 \pm 0.3$ & $2.5 \pm 1.3$ & $>8.2$ & $>8.2$ & 5.6 & 0.968 \\
\hline
\end{tabular}

TMC, total microbial count; CPS, coagulase-positive staphylococci; $\mathrm{A}_{w}$, water activity; CFU, colony forming units. ${ }^{\circ}$ Staphylococcal enterotoxins: not detectable. Results are expressed as mean \pm standard deviation.

Table 2. Results of microbiological and compositional analyses in raw milk and cheese at production and at different ripening stages in Toma cheese (producer B).

\begin{tabular}{|c|c|c|c|c|c|c|c|c|}
\hline Sample & TMC & E. coli & Enterobacteriaceae & CPS & $\begin{array}{l}\text { Lactic } \\
\text { acid streptococci }\end{array}$ & Lactobacilli & $\mathrm{pH}$ & $\mathbf{A}_{w}$ \\
\hline Raw milk (Log CFU/mL) & $5.9 \pm 0.5$ & 1.0 & $4.1 \pm 1.0$ & $2.2 \pm 0.6$ & $5.1 \pm 0.4$ & $4.5 \pm 0.7$ & 6.8 & - \\
\hline Milk at $38^{\circ} \mathrm{C}(\mathrm{Log} \mathrm{CFU} / \mathrm{mL})$ & $6.7 \pm 1.2$ & $1.6 \pm 0.6$ & $4.6 \pm 0.9$ & $2.9 \pm 0.7$ & $6.0 \pm 1.6$ & $5.8 \pm 1.6$ & 6.7 & - \\
\hline Curd (Log CFU/g) & $6.5 \pm 1.3$ & $2.4 \pm 1.3$ & $3.8 \pm 1.2$ & $3.2 \pm 0.6$ & $5.9 \pm 1.7$ & $5.7 \pm 1.5$ & 6.8 & - \\
\hline Cheese 7 days ( $\log C F U / g)$ & $>8.5$ & $4.6 \pm 0.5$ & $6.2 \pm 0.2$ & $4.8 \pm 0.9$ & $>8.2$ & $>8.2$ & 5.1 & 0.979 \\
\hline Cheese 30 days ( $\mathrm{Log} \mathrm{CFU} / \mathrm{g}$ ) & $8.3 \pm 0.3$ & $4.2 \pm 0.5$ & $5.0 \pm 1.1$ & $3.1 \pm 1.6$ & $7.8 \pm 0.3$ & $7.6 \pm 0.5$ & 5.5 & 0.967 \\
\hline Cheese 60 days ( $\mathrm{Log}$ CFU/g) & $7.9 \pm 0.4$ & $3.0 \pm 1.2$ & $3.8 \pm 0.2$ & $1.6 \pm 0.01$ & $7.6 \pm 0.2$ & $7.9 \pm 0.2$ & 5.7 & 0.931 \\
\hline Cheese 90 days ( $\log$ CFU/g) & $7.8 \pm 0.4$ & $2.0 \pm 1.2$ & $2.7 \pm 1.1$ & $1.5 \pm 0.9$ & $7.3 \pm 0.4$ & $7.8 \pm 0.1$ & 5.7 & 0.948 \\
\hline
\end{tabular}

TMC, total microbial count; CPS, coagulase-positive staphylococci; $\mathrm{A}_{w}$, water activity; CFU, colony forming units. ${ }^{\circ}$ Staphylococcal enterotoxins: not detectable. Results are expressed as mean \pm standard deviation. 
in the raw milk was 5.9 Log CFU/g and reached a maximum value of $8.5 \mathrm{Log} \mathrm{CFU} / \mathrm{g}$ in the cheese at 7 days of ripening, then decreased slightly at the end of the process. An increasing of CPS during the first phases of cheese production was observed, reaching a mean value of $4.8 \mathrm{Log} \mathrm{CFU} / \mathrm{g}$ at 7 days (a value of 5 Log was reached in two of three batches). Staphylococcal enterotoxins were not detectable. E. coli and Enterobacteriaceae developed during cheese production until 7 days of ripening, with maximum of $3.4 \mathrm{Log}$ CFU/g and 5.3 Log CFU/g, respectively, and at the end a decreasing level was found. Lactic bacteria increased until 7 days, then remained constant until the end of ripening with a count of about $7.8 \mathrm{Log} \mathrm{CFU} / \mathrm{g}$. The $\mathrm{pH}$ decreased during cheese process thanks to lactic flora, getting to an average of 5.1 at 7 days and 5.7 at the end. The $A_{w}$ decreased up to 60 days of ripening with a value of 0.948 in the final product. Results were summarised in Table 2.

\section{Discussion}

The present study might be a valid contribution regarding hygiene and food safety in cheese making process. The acquired data define the critical event in the process and this could be useful to identify the appropriate good manufacturing practices to be adopted by the staff involved in the process. The results obtained from both producers showed that the raw milk and the cheese samples were in compliance with the food safety criteria. Moreover, STEC, aflatoxin M1 and antimicrobial substances in the raw milk were not detectable.

Furthermore, it is known that the cheese making process can be affected by different factors, in particular during summer, when the temperature can influence the levels of coliforms, $E$. coli and CPS with negative effects on milk and dairy characteristics (Bernabucci and Calamari, 1998; Calamari and Mariani, 1998; Calamari et al., 2013). The situation in the Alpine dairy plant is more critical than in the valley, because of little arrangements and instruments that are difficult to sanitise and the lack of cooling devices for milk storage at farm level to slow down the growth of undesirable bacteria (Regione Lombardia, 2012).

For the producer A two batches were made in the Alpine dairy plant. Overall, the hygienic conditions of cheese making process were acceptable. E.coli and Enterobacteriaceae were more relevant in the first phases, however these parameters decreased at the end of ripening. The TMC increased in the first phases, like CPS, and both decreased at the end of ripening. In particular, the number of CPS resulted over the limit ( $>5 \mathrm{Log} \mathrm{CFU} / \mathrm{g}$ ) for the curd and cheese at 7 days in all batches, while in the cheese at 30 days the count was near the upper limit (4.8 Log CFU/g). On these samples, staphylococcal enterotoxins were negative. The origin of CPS detected in milk and in cheese could be different: these microorganisms may result from an occurring mastitis, often sub-clinical, in apparently healthy animals. Another source of contamination could originate from workers: staphylococci might be present in the human mucosa of the upper airways and the non-application of the good manufacturing practices may cause contamination of the milk. Therefore, it is required to keep low the CPS in the milk because of their ability to produce toxins when these bacteria exceed a value of 5 Log (Pelisser et al., 2009). The presence of hygiene indicator microorganisms (E.coli and Enterobacteriaceae), especially during the initial stages of cheese production, indicates that it is necessary to establish and respect good manufacturing practices to avoid contamination. During milk processing $\mathrm{pH}$ decreased due to the presence of lactic flora, and $A_{w}$ value decreased in the ripening period. The effect of ripening, the reduction of $\mathrm{pH}$ and $A_{w}$ values contributed to ensure the safety of dairy products (Brooks et al., 2012).

Considering producer $\mathrm{B}$, the problem of CPS was less important in the raw milk. In fact the count was lower than one logarithm in comparison with A (only in cheese at 7 days a value of 5 Log was reached, in two of three batches). The count decreased strongly with the ripening, until undetectable values in the final product. The trend of the indicator microorganisms was similar to producer A, but not totally overlapped, and stressed the importance of the correct application of good hygienic practices during the early stages of the production, as key moments of containment of these microorganisms. Also in this case the competitive activity of the lactic flora, together with the decrease of $\mathrm{pH}$ and $\mathrm{A}_{\mathrm{w}}$ values were fundamental to reduce the potentially pathogenic microbial loads during the ripening and to ensure the safety of dairy products (Brooks et al., 2012). The major decrease of $A_{w}$ value at 60 days noticed for the producer $\mathrm{B}$, in contrast with the producer $\mathrm{A}$, may be due to the difference between the two cellars of cheese ripening. In a previous study (Bellio et al., 2013), we focused on process hygiene criteria and food safety criteria of the same cheese (Toma tipo Piemonte) from other two producers. The results were similar to the present work: Enterobacteriaceae, E. coli and CPS were higher during the initial step of cheese production and decreased during the ripening period. Also in this case the food safety criteria tested were negative.

Another significant issue of the present work was the organisation of training courses for the two producers. The Manpower Services Commission (1981) defined training as $a$ planned process to modify attitude or skill behaviour through learning experience to achieve effective performance in an activity or range of activities (Manpower Services Commission, 1981). The knowledge obtained is kept unchanged for some years, and it is supposed to repeat the course after one or two years (Furnari et al., 2002). It is well documented that improper practices during food manipulation play a significant role in the occurrence of foodborne illness (Howes et al., 1996) and typically involve cross-contamination of raw and cooked foodstuffs, such as inadequate cooking and storage at inappropriate temperatures. In this study training activities were conducted by IZSPLV staff, in order to assess the critical steps of the cheese making process and perform or implement corrective actions in agreement with the producers. The IZSPLV staff supported the producers during the cheese making process, explaining the correct related behaviour for the milking process, for cheese making process in order to avoid cross-contamination, and at least the cleaning of the instruments related to both process (MiPAAF, 2014).

\section{Conclusions}

To conclude, the microbiological results obtained during sampling and analytical data acquired from the evaluation of the critical points, together with the training courses, allowed the suggestion of some measures to improve the hygienic quality of products. Finally, the most important key factor resulted to be the respect and application of good manufacturing practices, in order to obtain a product with high hygienic level and fulfilling the consumers' health.

\section{References}

Bellio A, Gallina S, Bianchi DM, Traversa A, Nogarol C, Perazzini AZ, Gramaglia M, Decastelli L, 2013. Valutazione delle condizioni igienico-sanitarie di produzioni lattiero-casearie d'alpeggio in Piemonte. Sci Tecn Latt Cas 64:29-33.

Bernabucci U, Calamari L, 1998. Effects of heat stress on bovine milk yield and composition. Zootec Nutr Anim 24:247-58.

Brooks JC, Martinez B, Stratton J, Bianchini A, Krokstrom R, Hutkins R, 2012. Survey of raw milk cheeses for microbiological quality and prevalence of foodborne pathogens. Food Microbiol 31:154-8.

Calamari L, Mariani P, 1998. Effects of the hot environment conditions on the main milk cheese making properties. Zootec Nutr Anim 24:259-71. 
Calamari L, Petrera F, Stefanini L, Abeni F, 2013. Effects of different feeding time and frequency on metabolic conditions and milk production in heat-stressed dairy cows. Int J Biometeorol 57:785-96.

European Commission, 2005. Regulation of the European Parliament and of the Council of 20 April 2005 laying down microbiological criteria applied to foodstuffs, 2073/2005/CE. In: Official Journal, L $338 / 1,22 / 12 / 2005$.

Furnari G, Molino N, Bruno S, Quaranta G, Laurenti P, Ricciardi G, 2002. Efficacy and critical implications of food handlers' professional training: analysis of an experience. Ann Ig 14:419-26.

Howes M, McEwan S, Griyths M, Harris L, 1996. Food handler certification by home study: measuring changes in knowledge and behaviour. Dairy Food Environ S 16:737-44.

ISO, 1996. Microbiology of food and animal feeding stuffs. Horizontal method for the detection and enumeration of Listeria monocytogenes. Part 1: detection method. ISO Norm 11290-1:1996. International Standardization Organization ed., Geneva, Switzerland.

ISO, 1999. Microbiology of food and animal feeding stuffs. Horizontal method for the enumeration of coagulase-positive staphylococci (Staphylococcus aureus and other species). Part 2: technique using rabbit plasma fibrinogen agar medium. ISO Norm 6888-2:1999. International Standardization Organization ed., Geneva, Switzerland.

ISO, 2001. Microbiology of food and animal feeding stuffs. Horizontal method for the enumeration of beta-glucuronidase-positive Escherichia coli. Part 2: colony-count technique at 44 degrees $\mathrm{C}$ using 5-bromo4-chloro-3-indolyl beta-D-glucuronide. ISO Norm 16649-2:2001. International Standardization Organization ed., Geneva, Switzerland.

ISO, 2003. Microbiology of food and animal feeding stuffs. Horizontal method for the enumeration of microorganisms. Colonycount technique at 30 degrees C. ISO Norm 4833:2003. International Standardization Organization ed., Geneva, Switzerland.

ISO, 2004a. Microbiology of food and animal feeding stuffs. Determination of water activity. ISO Norm 21807:2004. International Standardization Organization ed., Geneva, Switzerland.

ISO, 2004b. Microbiology of food and animal feeding stuffs. Horizontal methods for the detection and enumeration of Enterobacteriaceae. Part 2: colony-count method. ISO Norm 21528-2:2004. International Standardization Organization ed., Geneva, Switzerland.

ISO, 2004c. Microbiology of food and animal feeding stuffs. Horizontal methods for the detection of Salmonella spp. ISO Norm 6579:2002/Cor. 1:2004. International Standardization Organization ed., Geneva, Switzerland.

ISO, 2007. Microbiology of food and animal feeding stuffs. General requirements and guidance for microbiological examinations. ISO Norm 7218:2007. International Standardization Organization ed., Geneva,
Switzerland.

ISO, 2011. Microbiology of food and animal feed. Real-time polymerase chain reaction (PCR)-based method for the detection of food-borne pathogens. Horizontal method for the detection of Shiga toxin-producing Escherichia coli (STEC) and the determination of 0157, 0111, 026, 0103 and 0145 serogroups. ISO Norm 13136:2011. International Standardization Organization ed., Geneva, Switzerland.

Manpower Services Commission, 1981. Glossary of training terms. HMSO Publ., London, UK.

MiPAAF, 2014. List of Italian names entered in the register of protected designations of origin and protected geographical indications. Available from: http://www. politicheagricole.it/flex/cm/pages/ServeBL OB.php/L/IT/IDPagina/2090

Pelisser MR, Klein CS, Ascoli KR, Zotti TR, Arisi AC, 2009. Occurrence of Staphylococcus aureus and multiplex PCR detection of classic enterotoxin genes in cheese and meat products. Braz $\mathrm{J}$ Microbiol 40:145-8.

Povolo M, Pelizzola V, Passolungo L, Biazzi E, Tava A, Contarini G, 2013. Characterization of two Agrostis-Festuca alpine pastures and their influence on cheese composition. J Agr Food Chem 61: 447- 55.

Regione Lombardia, 2012. La formaggella della Valle di Scalve con il latte d'alpeggio. Available from: http://www.agricoltura.regione.lombardia.it/shared/ccurl/983 /569/QdR\%20147.pdf 